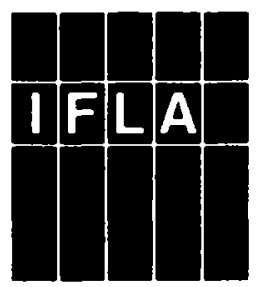


International Federation of Library Associations and Institutions

Fédération Internationale des Associations de Bibliothécaires et des Bibliothèques Internationaler Verband der bibliothekarischen Vereine und Institutionen Международная Федерация Библногечных Ассоцнацнй и Учреждения Federación Internacional de Asociaciones de Bibliotecarios y Bibliotecas 
IFLA Publications 58

\section{La Presse de la Liberté}

Journée d'études

organisée par

le Groupe de Travail IFLA sur les Journaux

Paris, le 24 août 1989

Seminar organised by the

IFLA Working Group on Newspapers

Paris, 24 August 1989

Edited by Eve Johansson 
IFLA Publications

edited by Carol Henry

Recommended catalogue entry:

La Presse de la Liberté: journée d'études organisée par

le Groupe de Travail IFLA sur les Journaux

Paris, le 24 aout 1989 /

Seminar organised by the IFLA Working Group on Newspapers

Paris. 24 August 1989 ;

Edited by Eve Johansson

München, New York. London, Paris: K. G. Saur, 1991

$122 \mathrm{p} ., 21 \mathrm{~cm}$

IFLA Publications 58

ISBN 3-598-21786-2

Die Deutsche Bibliothek - CIP-Einheitsaufnahme

La presse de la liberté : journée d'études organisée par la

Groupe de Travail IFLA sur les Journaux. Paris, le 24 août 1989

; [nternational Federation of Library Associations and

Institutions. Ed. by Eve Johansson]. - München ; London ; New

York ; Paris : Saur, 1991

(IFLA publications ; 58)

ISBN 3-598-21786-2

NE: Johansson, Eve [Hrsg.]: International Federation of Library

Associations and Institutions / Working Group on Newspapers; International Federation of Library Associations and Institutions: IFLA publications

(⿻)

Printed on acid-free paper

(C) 1991 by International Federation of Library Associations and Institutions. The Hague, The Netherlands Alle Rechte vorbehalten / All Rights Strictly Reserved K. G. Saur Verlag GmbH \& Co. KG, München 1991 Printed in the Federal Republic of Germany

Jede Art der Vervielfältigung ohne Erlaubnis des Verlags ist unzulässig.

Druck/Printed by Strauss Offsetdruck GmbH, Hirschberg Binden/Bound by Thomas Buchbinderei, Augsburg

ISBN 3-598-21786-2

ISSN 0344-6891 (IFLA Publications) 